\title{
Modified Research on Children's Medical Space on the Basis of Place Spirit
}

\author{
Dunjiang Shang \\ Tan Kah Kee College, Xiamen University, Zhangzhou Fujian, 363105, China
}

Keywords: Place spirit, Children, Medical environment.

\begin{abstract}
In modern society, people have higher and higher requirements on medical environment, on the basis of space place spirit analysis, space designers analyze the physiological and psychological feelings of place spirits, combine the special property of children's space, from the angle of place space design to avoid the coldsense of children's medical space under the high-tech model to construct a comfortable medical space atmosphere with sense of security, to meet the usage and aesthetic property of children' s medical space, to make a reasonable expression for the place spirit of medical environment, to construct a space to meet users' perceive and behavioral requirements to increase humanistic care for children's medical environment.
\end{abstract}

\section{Introduction}

With people's concern on their health and the rapid development of modern medical level, people have a deeper understanding on medical environment requirements, the use form of medical environment cares more about patients' psychological feelings. Medical space changes from places for basic saving lives, doctor \& pharmacy to care more about patients' mental experiences on the premise of meeting basic functions, to release patients' pessimistic performance like mental stress and unease. Especially the disadvantage group--children who have no active medical ability should be paid with more attention.

\section{Interpretation on the relationship between place spirit and children's medical space experience}

Experience on place space is usually experiencers' physiological and psychological visual perception experience by using sensory organs, this kind of place spirit is normally specified experience. Among the features of spatial experience, place structure is correlated and unified with place spirit. Place structure here means the basic function of space, while place spirit means the experiencers' psychological feelings on space functions through perceptual experience on the basis of the basic function of space. Therefore, what corresponds to the psychological process of "space" and "features" in the place structure is the psychological feelings of "sense of security" and "sense of identity" of place spirit.

Through research on the using object group of children's medical environment we know that the main usage groups include three direct use groups that children patient, accompanying family members and medical staffs. Among which, three use groups are correlated and influenced by each other, its main service objects are children patients. From the behavior state and spiritual demand of children patients, accompanying family members and medical staffs, they have similarity. Therefore, construct reasonable layout and place spirit for space according to the demand of main service objects, maximum to meet and coordinate the relationship between the behavior state and spiritual demands of different uses. The followings are analysis on the behavioral features and habits of the behavioral agents in the children's medical space:

\section{Analysis on children patients' behavior state and behavioral habit.}

In the medical space, children patients' physiology and psychology are in a state of sub-health, they feel unwell for sickness, they are hard to describe their own symptom, while suddenly enter a strange space, they feel scared, alone and anxious. From children patients' behavioral habits we know 
that because of the physiological and psychological immaturity, compared with adult patients, children patients have their special behavioral habits and spiritual demands, such as during the medical process, many children patients usually behave panic, irritable, crying and incoordination during their contacts with medical staffs.

Analysis on the behavior state and behavioral habits of accompanying family members and medical staffs.

During the medical process, children patients cannot directly express their own feelings for the physical and mental reasons, accompanying family members are usually with heavy mental stress and anxiety, especially under the situation that not clear about children patients' sickness, family members of the patients are easy to be with psychological fluctuation and high pressure, feel restless, they are eager to communicate with medical staffs, they worry about children patients' physical condition, feel anxious, hope patients to get well soon, they are hard to get relax and rest, especially when face with the cold medical space, their psychological changes complicated and have no sense of security and identity in the scene space.

Medical staffs in the medical space, for their long term contacts with children patients and patient family members, they are with large working strength, spiritual stress and high tension mental state. They usually have physical and mental double pressures. During the medical process, the relationship among medical staffs, children patients and accompanying family members is abnormal, because of the noisy working environment,their spirit and behavior are easy to for the negative state of impatience, depression and loss.

Accompanying family member and medical staffs' behaviors will affect children patients' therapeutic effects, as the adult group, they have same behavioral habits and spiritual needs, through field observation research we summarized the general characteristics of family members and medical staffs' behaviors and habits during the medical space: (1) Crowd mentaily like convergence and curiosity. (2) Be anxious for success. (3) Unsafe psychology.

\section{Analysis on the place spirit demand of behavioral agents in children's medical space}

Through the analysis on the behavior state and behavioral habits of behavioral agents in the medical space, we summarized people's place spirit demand in the medical space. This kind of demand form must be met through the place spirit of children patients, accompanying family members and medical staffs. Including:

\section{Privacy requirement of place spirit.}

In children's medical space, a relative private and close space usually can help behavioral participants calm down and have a certain psychological sense of security. This is very important for children patients who are in physical and mental sub-health status during the medical process. Provide a private environment and the pleasant private space for children patients and their family members is benefit for their recovery.

\section{Territoriality demand of place spirit.}

In rather strange space, people are tend to have their own independent space, they don't like other people occupy their psychological space, this kind of psychological behavior is called as territoriality. For children, who are not good at expressing, their occupying for tools shows their territoriality. Therefore, in medical space design, children's safe territoriality is worthy attention.

\section{Ecological demand of place spirit.}

In natural environment, green plants can make people calm and happy. People are prone to close to nature. Therefore, in the cold children medical space, children are curious, then like blue sky, green plants and water, using green plants to soften the coldness of space, to help children relax, release their physical and mental stress.

\section{Enjoyment demand of place spirit.}

Children like to stay in the space with bright colors and cartoon images, this kind of lively space can attract children's attention. Because children's attention diversion can produce cheerful mood, to 
some extent, it can relieve their pain and are benefit for their rehabilitation.

\section{Safety and health demand of place spirit.}

In medical space, patients carry a lot of bacteriovirus, in sickness, children patients' body resistance reduced obviously. We must do a good job of disinfection everyday. Meanwhile, children are difficult to stay in a place quietly, they walk around, all kinds of facilities in the space shall not be sharp to prevent children being injured.

\section{Specific strategy of place spirit in children's medical space}

\section{Give space emotional connotation.}

Among experiencers' perception on spatial experience, they convey their psychological feelings on safety behaviors through their position in the spacial environment. Behavioral agents' good spacial experience endows space with good emotional connotation. In children's medical experiences,there are many people, people groups are also complicated, we have to grasp the psychological feelings on emotional connotation correctly. A space with good emotional connotation and special theme can affect behavioral agents' behavioral demand and emotional expression. Therefore, in children's medical space design, we need to carefully analyze children patients' physical behavior and psychological expression, start from whole space design, focus on the construction of place spirit, help children to distract attention in the space, to help them relax, through providing children's medical space with emotional connotation to help children patients and family members feel safe and trust, thus medical staffs can feel sense of belonging.

Fully meet behavioral agents' behavioral requirements.

As the main user group of the space, behavioral agents' behavior determines the function attributes of the space, the formation of this kind of functional attribute also determines space environment at the same time, meanwhile, the construction of space environment deepen behavioral agents' degree of participation. If behavioral agents meet the behavioral requirement in the space, their satisfaction on place spirit will be high. On the contrary, it will reduce. Therefore, the construction of place spirit must be based on meeting behavioral agents' behavioral psychology and behavioral requirements to realize the fusion of feelings with the natural setting. In children' $s$ medical space design, mainly focus on its function of providing medical assistance for children, meanwhile we also shall consider their family members and medical staffs' psychological factors, this two kinds of people have positive function on children patients' treatment.

\section{Pay attention to the construction of outdoor environment place spirit.}

In children's medical space design, the construction of place spirit not only emphasizes on indoor space, but also needs to consider the construction of outdoor environment place spirit. Through field research and observation, we found that in Chinese children's medical spaces, both designer and manager lay their design and using emphasis on the construction of indoor place spirit, while the behavioral agents of the spaces--children hope to play and run freely in outside, accompanying family members and medical staffs hope to relax and adjust spirit state and take a fresh breath in outside, more importantly, construction of outdoor environment place spirit is benefit for children patients' physical and mental disease treatment and recovery.

Construction of the "family" atmosphere of place spirit.

For children patients, feelings in the medical space will affect their psychological changes in the medical progress, if children patients enter a strange and cold space, they will produce a panic and alone emotion, they usually will show psychological feelings of incoordination, fighting and wanting to escape in their treatment. If children patients enter a relative familiar and trusted environment, their psychological inimical emotion will reduce, during their treatment interaction with medical staffs, children patients will be coordinate positively. If they enter a rather strange medical space, the boring color, adult equipment will bring them with insecurity. On the contrary, if children patients enter a relative familiar and intimacy "family" medical space, their insecurity will be reduced on some extent, and is benefit for recovery. Therefore, in children patient's medical spaces, in order to provide this 
kind of familiar and safe scene, "family" atmosphere construction is a direct design method for designers.

\section{Aesthetic psychological needs that conform to behavioral agents.}

Analyzing children from psychology can feel aesthetic taste intuitively, compared with bright pure colors, like yellow, green, blue, red, this kind of bright colors can improve children' s excited degrees, make children feel active and cheerful. On the perception of the graphics, they are tend to colorful and interesting paintings, if there are cartoon images and cartoon stories in the space, it will arouse children's resonance on these paintings, this will eliminate strangeness, release their anxiety. These emotional aesthetic psychology is determined by children' s nature of curiosity and activity. In such kind of scenes with fairy tale characters, they are easy to get into the scene and full with sense of belonging for the place spirit experience. Thus to release children patients' negative emotions, change the negative treatment into active communication with medical staffs and actively coordinate with doctors. In children' medical space, designers respect behavioral agents' aesthetic psychological needs, through bright color contrast, interesting pictures changeable space form ti improve the place spirit. At the same time, in the scene design process, we also need to consider the adult aesthetic psychology of family members and medical staffs.

\section{Introduction of non medical sites into children's medical space.}

In children's medical space, the meaning of place spirit existence is a connective and story logic relation. In children's medical space, the arrangement of space function shall give priority to medical blocks, meanwhile revolve with preventive education, rehabilitation care and other functions. Behavioral agents' requirements on medical space is not just limited in treatment function, psychological care is more important. In children's medical process, they are normally treated passively. Usually, children's lively personality is difficult for quiet treatment. If set corresponding region for playing, activity, entertainment and study, children patients are often willing to take part in it. It is convenient for children to stay in the space for a long time, and has positive function on children's recovery. Such as fun activity room, psychological counseling room, drawing room, sun plant room and so on. For family members and medical staffs, in order to release children patients' tension stress in the medical process, setting some non medical scene is very important. Such as some small book store, coffee shop, store, gymnasium and other such kind of leisure spaces.

\section{References}

[1] Zhang Yu. Research on the Children Medical Environment Design on the Basis of New Medical Model. Harbin: Harbin Institute of Technology. 2008.

[2] Zhang Jia. Research on the Hospital Public Space Design Strategy on the Basis of New Medical Model. Harbin: Harbin Institute of Technology. 2005.

[3] Wang Kexin. Research on the Color Application in Children Bedroom Design. Harbin: Northeast Forestry University.2010.

[4] Ye Chunxiang. Pediatric Nursing. Beijing: People's Medical Publishing House.2013.

[5] Chang Hong. Evaluation and Guidance on Children's Growth and Development, China's Rural Doctors Magazine.2011,5.

[6] Liu Hongxia. Research on the Environment Design of Hospital Pediatric Care Unit. Changchun: Jilin Construction Engineering College. 2012.

[7] Li Wei, Zhang Shizhong. Encyclopedia of Mental Health-Child health. Shanghai: Shanghai Education Press. 2004.

[8] Li Hong. Pediatric Psychology. Beijing: People's Education Press.2007. 